\title{
Subtype distribution of Haemophilus influenzae isolates from North India
}

\author{
A. SHARMA, R. KAUR, N. K. GANGULY, P. D. SINGH and A. CHAKRABORTI \\ Department of Experimental Medicine and Biotechnology, Postgraduate Institute of Medical Education and \\ Research, Chandigarh, India
}

\begin{abstract}
A total of 120 Haemophilus influenzae isolates from blood, cerebrospinal fluid, sputum and throat swabs of patients and carriers in North India was characterised by biotyping, ribotyping and random amplification of polymorphic DNA (RAPD)-PCR. Of these, 77 isolates $(64 \%)$ were serotype $b$; the other $43(36 \%)$ were non-typable. Biotype $I$ was the most predominant among the typable strains and biotype II among the non-typable strains. Ribotyping with restriction endonucleases HaeIII and EcoRI differentiated the isolates into three and six ribotypes, respectively. However, RAPD fingerprints generated by the application of arbitrary primers AP1 and AP2 provided a higher level of discrimination. RAPD typing revealed distinct polymorphism among the serologically typable isolates. This study is the first report that stratifies the subtypes of $\mathrm{H}$. influenzae strains from India by molecular techniques.
\end{abstract}

\section{Introduction}

Haemophilus influenzae, although a common commensal of the upper respiratory tract of healthy individuals [1], is an important pathogen. The species is divided into six capsular types on the basis of production of a polysaccharide capsule [2] of which type b is a frequent cause of meningitis and other invasive disorders in children [3]. The non-capsulate strains also cause a wide spectrum of clinical infections including chronic bronchitis, pneumonia and bacteraemia, and are found in $75 \%$ of healthy individuals [4].

In India, $96 \%$ of all haemophilus infections are caused by $H$. influenzae serotype b (Hib) [5]. Since the mid1950s, Hib has been the most common cause of pyogenic meningitis in children in India. The burden of invasive Hib is substantial, with the incidence of Hib meningitis estimated to be $50-60$ cases $/ 100000$ children $<5$ years of age [6]. A study from Delhi has also reported Hib to be a common cause of pneumonia in $19 \%$ of cases in children [7]. The outcome has not changed significantly in the past decade despite the introduction of potent antibiotics.

The large and genetically diverse pool of H. influenzae

Received 7 Aug. 2001; revised version accepted 27 Nov. 2001.

Corresponding author: Dr A. Chakraborti (e-mail: superoxide (a)sify.com). strains circulating in the community has been documented previously [8]. Therefore, the availability of high resolution typing assays is a prerequisite for the study of $H$. influenzae epidemiology. The investigation and comparison of outbreaks of infection have been hampered by the lack of standardised, highly discriminatory methods for characterising the strains. The use of several molecular typing techniques for the effective detection of outbreaks of infection as well as identification of new and infectious clones of $H$. influenzae has been reported in recent years $[9,10]$. Among these, restriction fragment length polymorphism analysis with ribosomal RNA (rRNA) as the probe [11-13] has been used widely to differentiate isolates into ribotypes. Intra-specific genetic variation can also be detected by randomly amplified polymorphic DNA (RAPD) analysis. In RAPD, the amplicons, when arrayed by electrophoresis, yield fingerprints which differ depending on the relatedness of the genomic templates [14].

The aim of this study was to characterise the $H$. influenzae isolates from patients and carriers by biotyping, ribotyping and RAPD fingerprinting and thus to analyse the subtype distribution of isolates from India.

\section{Materials and methods}

Study population

Seventy-seven $H$. influenzae type $\mathrm{b}$ isolates from cerebrospinal fluid (CSF) and blood samples of infants 
(aged $<1$ year) suffering from meningitis and bacteraemia, respectively, attending clinics at the Postgraduate Institute of Medical Education and Research, Chandigarh, India, were examined. Forty-three nontypable isolates were cultured from throat swabs of children (aged 5-15 years) and adults (aged 2340 years) with informed consent and from the sputum of patients (aged 25-35 years) suffering from chronic bronchitis. Patients with a history of antibiotic therapy and those currently receiving antibiotics were excluded. All the samples were collected between March 1997 and July 2000.

\section{Bacterial isolates}

The samples collected from the patients and carriers were cultured on $7 \%$ chocolate agar in an atmosphere containing $\mathrm{CO}_{2} \quad 5 \%$. H. influenzae isolates were identified by their typical colony morphology and growth requirements for NAD and haemin. Serotyping was performed by slide agglutination tests with antisera to the capsular antigens $\mathrm{a}-\mathrm{f}$ (Difco). Biotypes were assigned by testing $H$. influenzae isolates for the ability to produce urease, indole and ornithine decarboxylase by the method of Kilian [15]. The isolates were stored at $-70^{\circ} \mathrm{C}$ in Brain Heart Infusion Broth (Difco) supplemented with glycerol $5 \% \mathrm{v} / \mathrm{v}$.

\section{Preparation of genomic DNA}

Genomic DNA was extracted by a modification of the method described by Pitcher et al. [16]. Briefly, the bacterial colonies from overnight cultures were suspended in $150 \mu \mathrm{l}$ of TE buffer $(10 \mathrm{mM}$ Tris- $\mathrm{HCl}, 1 \mathrm{mM}$ EDTA, $\mathrm{pH}$ 8.0) and lysed by adding $450 \mu \mathrm{l}$ of solution containing $5 \mathrm{M}$ guanidium thiocyanate, $100 \mathrm{mM}$ EDTA and sarkosyl $0.5 \% \mathrm{v} / \mathrm{v}$. After incubation at $4^{\circ} \mathrm{C}$ for $10 \mathrm{~min}, 7.5 \mathrm{M}$ cold ammonium acetate was added. The DNA was extracted with phenol-chloroform, precipitated with ethanol and finally dissolved in TE. DNA preparations from different samples were quantified spectrophotometrically and stored at $-20^{\circ} \mathrm{C}$ for further use.

\section{Ribotyping}

Genomic DNA $(10 \mu \mathrm{g})$ digested with restriction endonucleases HaeIII and EcoRI (Roche, Germany) was separated in agarose $0.8 \%$ gel. Southern hybridisation was performed by standard procedures [17]. The probe used was a synthetic oligonucleotide (5'-AAG AGT TTG ATC CTG GCT CAG-3') from bacterial $16 \mathrm{~S}$ rRNA (Biobasics, Canada) and was prepared by endlabelling with $\gamma^{32}$ P-ATP (BRIT, Hyderabad, India). The membranes were hybridised with the probe, washed and autoradiographed by exposure to X-ray film by the method of Bruce and Jordens [9].

\section{RAPD fingerprinting}

RAPD analysis was performed with primers (Genset, Singapore) AP1 (5'-AAG TAA GTG ACT GGG GTG AGC G-3') and AP2 (5'-ATG TAA GCT CCT GGG GAT TCA C-3') which were arbitrarily chosen from enterobacterial repetitive intergenic consensus sequences. PCR amplification was performed in a $25-\mu 1$ volume mixture containing $100 \mathrm{ng}$ of template DNA, $200 \mu \mathrm{M}$ dNTPs, $200 \mathrm{ng}$ of primer and 1 unit of Taq polymerase (Roche, Germany). The reaction mixtures were overlaid with a drop of sterile mineral oil (Sigma) in each PCR tube to avoid evaporation during cycling. A negative control containing all the ingredients except template DNA was run in parallel to each PCR experiment. After an initial denaturation for $5 \mathrm{~min}$ at $94^{\circ} \mathrm{C}$, the PCR was performed for 35 cycles in an automated thermal cycler (Perkin-Elmer Cetus, USA) programmed for denaturation at $94^{\circ} \mathrm{C}$ for $1 \mathrm{~min}$, annealing at $25^{\circ} \mathrm{C}$ for $1 \mathrm{~min}$ and extension at $72^{\circ} \mathrm{C}$ for $4 \mathrm{~min}$. The amplification reactions were repeated three times to check the reproducibility of the RAPDPCR banding profiles. The final extension time was $10 \mathrm{~min}$ at $72^{\circ} \mathrm{C}$. The amplification products $(12 \mu \mathrm{l})$ were electrophoresed in agarose $1 \%$ gels (FMC Bioproducts, USA) in Tris-borate-EDTA buffer containing ethidium bromide $0.5 \mu \mathrm{g} / \mathrm{ml}$. These gels were visualised in a UV transilluminator (Fotodyne, USA) and photographed. Appropriate DNA mol. wt markers were used for sizing the bands in the gel. Finally, RAPD-PCR bands were interpreted by visual analysis of the polaroid pictures.

\section{Discriminatory power of the typing methods}

The discriminatory ability of each typing method shown in Table 2 was determined by calculating the numerical discrimination index (DI) by the method of Hunter and Gaston [18]. A DI of 1.0 indicates that the typing method is able to distinguish each strain from the test population. Conversely, a DI of 0 indicates that all the strains of the test population are indistinguishable.

\section{Results}

Genetic polymorphism of $H$. influenzae strains prevalent in India was studied by biotyping, ribotyping and RAPD analysis and compared for epidemiological purposes. The results of these typing techniques are summarised in Table 1. A total of 305 cerebrospinal fluid (CSF) and 41 blood samples from infants (aged $<1$ year) suffering from meningitis and bacteraemia, respectively, was screened; $73 \mathrm{H}$. influenzae serotype b isolates were obtained from CSF and 4 from blood. The throat swabs of 40 healthy children (aged 5-15 years) and 23 adults (aged 23-40 years), and the sputum samples of 25 patients (aged 25-35 years) suffering from chronic bronchitis were also screened; 25,10 and 
8 non-typable isolates were obtained from the respective groups. Seventy-seven strains (64\%) were serotype $\mathrm{b}$ and $43(36 \%)$ were non-typable. A few type b strains that were isolated from the throat swabs of a healthy carrier population were not included in the study. Other capsulate serotypes of $H$. influenzae, i.e., a, c, d, e and f, were not observed.

Biotyping differentiated the set of isolates into six biotypes; biotypes VI and VIII were not found (Table 1). Biotypes I, II and III were common among both the serotype $\mathrm{b}$ and non-typable isolates. Biotype I was predominant $(40 \%)$ among the typable strains in the study population, although most of the non-typable isolates (39\%) were of biotype II. Biotypes IV and V were found only in the typable isolates while biotype VII was associated only with the non-typable isolates.

Ribotyping with HaeIII restriction endonuclease discriminated the $H$. influenzae isolates into three ribotypes, each characterised by the presence of four or five fragments of differing size ranging from $0.5 \mathrm{~kb}$ to $4.4 \mathrm{~kb}$ (Fig. 1a). Ribotype A was the most prevalent among both the typable (66\%) and non-typable (51\%) isolates (Table 1). Ribotype analysis on digestion with EcoRI revealed six distinct banding patterns, with band size ranging from 0.5 to $10 \mathrm{~kb}$ (Fig. 1b, Table 1) of which ribotype $\mathrm{E}$ was the most common among both serotype b (36\%) and non-typable (49\%) isolates. However, EcoRI restriction allowed minor differentiation among the non-typable isolates.

Intra-serotypic variation was also evident by RAPD fingerprinting. The $H$. influenzae isolates exhibited marked heterogeneity with each of the arbitrary primers AP1 and AP2. Arrays of fragments ranging from $0.2 \mathrm{~kb}$ to $1.5 \mathrm{~kb}$ in size were observed. All the major and minor bands that were reproducible by repeated experiments were scored. The serotype $b$ isolates showed 10 distinct banding patterns with primer AP1 (Fig. 2a), although it did not allow any differentiation among the non-typable isolates. RAPD type $\mathrm{g}$ was the most common among the serotype $\mathrm{b}$ isolates $(21 \%)$ and was shown by all the non-typable isolates (Table 1). Primer AP2 provided the highest level of discrimination with a DI value of 0.925 (Table 2) among the isolates where variation in both number and size of bands could be observed in the fingerprints (Fig. 2b). Each of the RAPD patterns of the nontypable isolates was distinct from those of the type $b$ isolates. AP2 could also differentiate the non-typable isolates that showed similar profiles with AP1. Therefore, AP2 was found to be more discriminatory than primer AP1 (Table 2).

Among the typable $H$. influenzae isolates from blood, there was complete concordance between ribotyping with EcoRI and RAPD fingerprinting with both the primers. Three of the four isolates from blood were of ribotype A with EcoRI and RAPD type a with AP1 and 

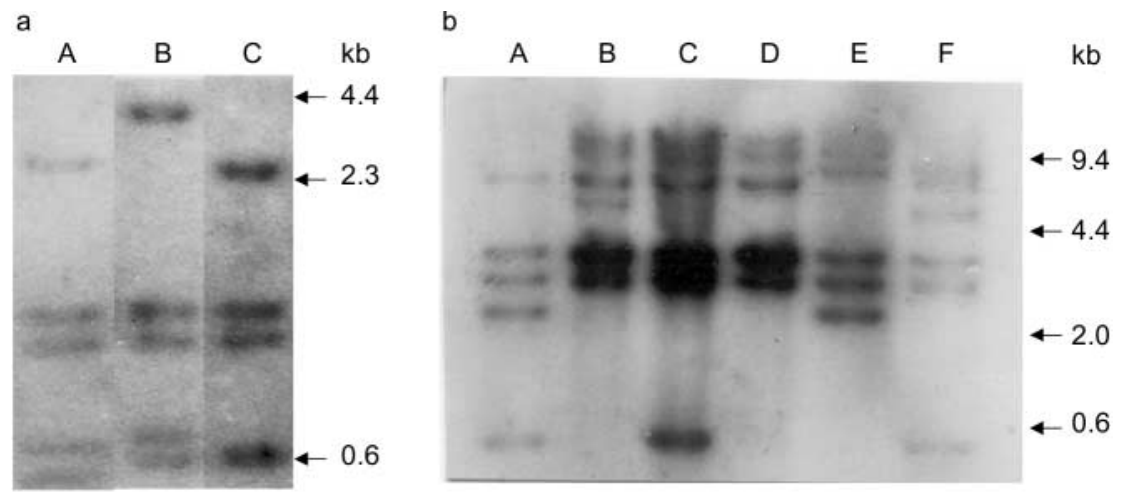

Fig. 1. Genomic ribotyping pattern of different subtypes of $H$. influenzae isolates following restriction enzyme digestion with (a) HaeIII, (b) EcoRI. Numbers indicate the molecular size corresponding to the marker ( $\lambda$ DNA, digested with HindIII).

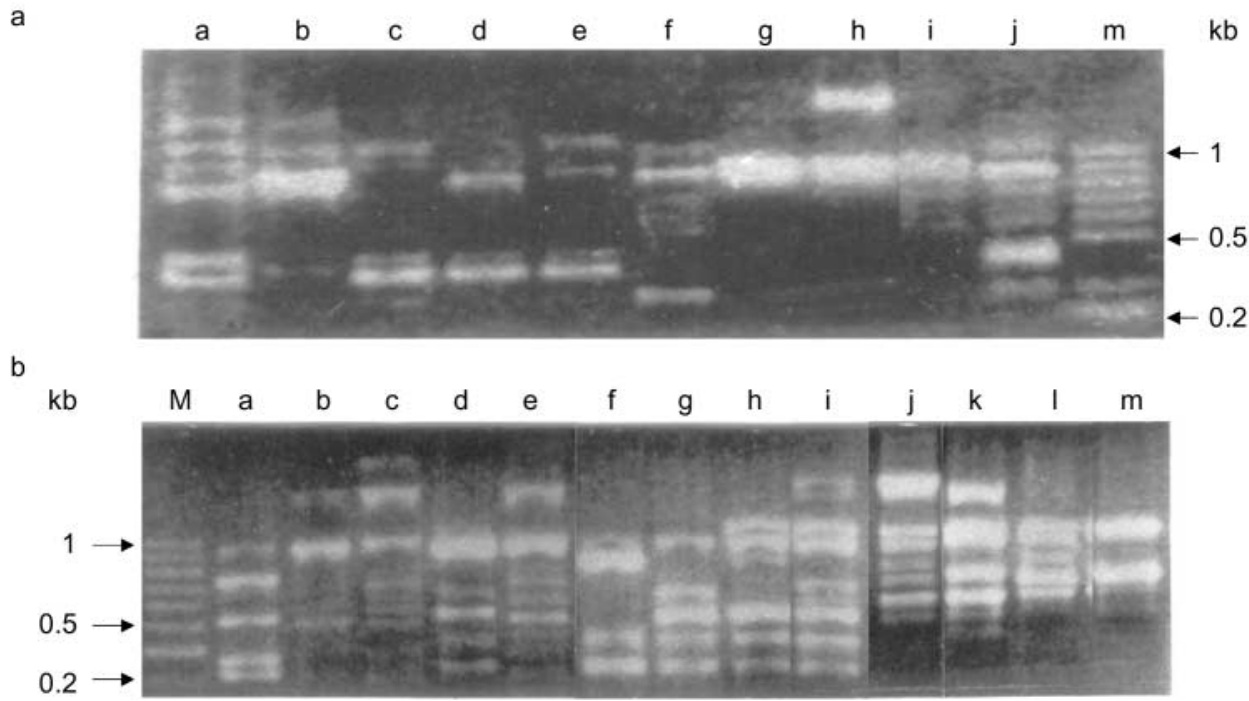

Fig. 2. RAPD-PCR amplification pattern of different subtypes of $H$. influenzae isolates with (a) AP1 primer, (b) AP2 primer. M, DNA molecular size marker.

Table 2. Discrimination indices [18] for the typing methods for $H$. influenzae

\begin{tabular}{lcc}
\hline Typing method & $\begin{array}{c}\text { Number of Discrimination index } \\
\text { types }\end{array}$ & (DI) \\
\hline Biotyping & 6 & 0.731 \\
Ribotyping with HaeIII & 3 & 0.558 \\
Ribotyping with EcoRI & 6 & 0.743 \\
RAPD fingerprinting with AP1 & 10 & 0.729 \\
RAPD fingerprinting with AP2 & 13 & 0.925 \\
\hline
\end{tabular}

AP2 whereas one isolate was of ribotype D and RAPD type $\mathrm{d}$, respectively. All these four isolates belonged to ribotype A on digestion with HaeIII. Six of the isolates from the CSF samples belonged to ribotype A with the enzymes (EcoRI and HaeIII) and RAPD type a with both the primers and hence gave concordant profiles with all four genotyping methods.

Among the non-typable isolates, all eight isolates from the sputum samples of patients with chronic bronchitis showed complete concordance with HaeIII ribotyping and RAPD analysis with both the primer sets. These samples showed ribotype A with HaeIII and RAPD type $\mathrm{g}$ and $\mathrm{k}$ with primers AP1 and AP2, respectively. EcoRI digestion further differentiated five of these isolates into ribotype $\mathrm{A}$ and three into ribotype $\mathrm{E}$. However, the non-typable isolates from the throat swabs of the healthy carrier population demonstrated discordant results and were randomly distributed over the various subtypes.

\section{Discussion}

$H$. influenzae causes a wide spectrum of conditions that range from asymptomatic colonisation of the upper respiratory tract to serious infections such as meningitis. H. influenzae type $\mathrm{b}$ is a leading cause of bacterial meningitis and other invasive infections in childhood world-wide. In India, the annual incidence of Hib meningitis has been quite high and results in severe morbidity and mortality in children $<5$ years of age $[5,6]$. In the present investigation also, $24 \%$ (73 of a 
total 305) of the CSF and $10 \%$ (4 of 41) of the total blood samples screened were found to be positive for H. influenzae serotype $\mathrm{b}$, which indicates a high prevalence of Hib-associated meningitis. Despite early diagnosis and appropriate treatment, Hib infection has been difficult to control and continues to pose an extensive health burden. Hence, there is an urgent need to study the epidemiology of $H$. influenzae in this community.

The ability to detect more subtle variations has increased substantially with the development of highly sensitive molecular techniques [9, 10]. Ribotyping [19] and RAPD-PCR $[20,21]$ have been used for detecting polymorphism within medically important organisms. However, the value of any typing procedure depends on the discriminatory power of the particular technique being applied.

Subtyping of $H$. influenzae by protein analysis has been done with strains from North America, Europe and UK $[22,23]$. Molecular studies have also been done with these strains [24,25] and also with Australian [26] and Japanese strains [27]. However, there has been a dearth of data on molecular analysis of strains from India. Hence we have, for the first time, subtyped $H$. influenzae isolates from India by genotypic methods.

In the USA, $>95 \%$ of invasive $H$. influenzae are of serotype $b$ and biotype I $[28,29]$. In Western Europe, only biotypes I and II are prevalent in most countries although biotypes III, IV and V have also been detected [30]. In Japan, $73 \%$ of Hib strains belong to biotype I, $20 \%$ to biotype II and the remainder to biotype III. Serotypes a and c (found occasionally) are associated with biotypes I and I or IV, respectively, while the serologically non-typable isolates are distributed among all the eight biotypes, predominantly biotypes II and III [31]. In developing countries, $70-80 \%$ of $H$. influenzae strains are of serotype b. In a study from Pakistan, 64\% of the samples screened were of serotype $b$ and $98 \%$ of them belonged to biotype II [32]. However, in the present study, biotype I was the most predominant among the Hib strains, followed by biotype II among the serologically non-typable isolates. Interestingly, biotypes VI and VIII were not found in the population.

Several studies have used molecular strategies for typing $H$. influenzae. Ribotyping and RAPD analysis of strains from the UK revealed considerable heterogeneity among the non-typable isolates [23]. Brazilian strains have shown the existence of 15 ribotype patterns, 3 of which are associated most frequently with purpuric fever [24]. On amplification by longPCR, the ribosomal operons of the non-typable strains of $H$. influenzae from Australia, have been found to be highly polymorphic for internal HaeIII sites [26]. In a recent study from Japan, long-PCR ribotyping of the strains did not allow any differentiation among the Hib isolates on digestion with HaeIII. On the other hand,
RAPD analysis of these strains showed two distinct patterns that were biotype-specific [27]. In the present study, the ribotypes obtained with HaeIII restriction endonuclease generated three banding profiles and were almost similar for the typable and non-typable isolates. Highly polymorphic bands were observed among the typable isolates with EcoRI, although non-typable isolates did not reveal much heterogeneity (Fig. 1, Table 1).

In the present study, the arbitrary primers AP1 and AP2 used for RAPD analysis are from the enterobacterial repetitive intergenic consensus sequences. These sequences are highly conserved and are able to show discrimination in many other organisms [33, 34]. In the present study, variations within the typable strains were observed by AP1 primer PCR fingerprinting. However, the non-typable $H$. influenzae demonstrated no differentiation with this primer. Primer AP2 was found to be more discriminatory and was able to show variations even within the serologically non-typable strains. Genotypic typing of the Indian $H$. influenzae isolates showed a high DI value by RAPD fingerprinting.

The data further reveal concordance of profiles with the isolates from blood, sputum and a few of the CSF samples from the respective patient groups by both ribotyping and RAPD-fingerprinting. This was in contrast to isolates from normal individuals, which presented random profiles.

In conclusion, the ability to identify strain variants appearing during persistent $H$. influenzae infections indicates that RAPD-fingerprinting is suitable for revealing genotypic diversity within serotypes. This typing method may be useful in the investigation of outbreaks of infection as it is quick to perform, requires modest effort and no previous genetic knowledge of the target organism is needed.

\section{References}

1. Turk DC, May JR. Distribution of Haemophilus influenzae in healthy human communities. In: Haemophilus influenzae: its clinical importance. London, English Universities Press. 1967: 13-23.

2. Pittman M. Variation and type specificity in the bacterial species Haemophilus influenzae. J Exp Med 1931; 53: 471-493.

3. Redmond SR, Pichichero ME. Haemophilus influenzae type $\mathrm{b}$ disease. An epidemiological study with special reference to day-care centers. JAMA 1984; 252: 2581-2584.

4. Trottier S, Stenberg K, Svanborg-Edén C. Turnover of nontypeable Haemophilus influenzae in the nasopharynges of healthy children. J Clin Microbiol 1989; 27: 2175-2179.

5. Singhi S, Singhi P, Baranwal AK. Bacterial meningitis in children: critical care needs. Indian $J$ Pediatr 2001; 68 737-747.

6. John TJ, Cherian T, Raghupathy P. Haemophilus influenzae disease in children in India: a hospital perspective. Pediatr Infect Dis J 1998; 179 Suppl: S169-S171.

7. Bahl R, Mishra S, Sharma D, Singhal A, Kumari S. A bacteriological study in hospitalized children with pneumonia. Ann Trop Paediatr 1995; 15: 173-177.

8. Musser JM, Barenkamp SJ, Granoff DM, Selander RK. Genetic 
relationships of serologically nontypeable and serotype b strains of Haemophilus influenzae. Infect Immun 1986; 52: $183-191$.

9. Bruce KD, Jordens JZ. Characterization of nonencapsulate Haemophilus influenzae by whole-cell polypeptide profiles, restriction endonuclease analysis, and rRNA gene restriction patterns. J Clin Microbiol 1991; 29: 291-296.

10. Lipuma JJ. Molecular tools for epidemiologic study of infectious diseases. Pediatr Infect Dis J 1998; 17: 667-675.

11. Leaves NI, Jordens JZ. Development of a ribotyping scheme for Haemophilus influenzae type b. Eur J Clin Microbiol Infect Dis 1994; 13: 1038-1045.

12. Grimont F, Grimont PAD. Ribosomal ribonucleic acid gene restriction patterns as potential taxonomic tools. Ann Inst Pasteur Microbiol 1986; 137: 165-175.

13. Maslow JN, Mulligan ME, Arbeit RD. Molecular epidemiology: application of contemporary techniques to the typing of microorganisms. Clin Infect Dis 1993; 17: 153-164.

14. Myers LE, Silva SVPS, Procunier JD, Little PB. Genomic fingerprinting of "Haemophilus somnus" isolates by using a random-amplified polymorphic DNA assay. J Clin Microbiol 1993; 31: $512-517$.

15. Kilian M. A taxonomic study of the genus Haemophilus, with the proposal of a new species. J Gen Microbiol 1976; 93: $9-62$.

16. Pitcher DG, Saunders NA, Owen RJ. Rapid extraction of bacterial genomic DNA with guanidium thiocyanate. Lett Appl Microbiol 1989; 8: 151-156.

17. Sambrook J, Fritsch EF, Maniatis T (eds). Molecular cloning: a laboratory manual, 2nd edn, vol 2. Cold Spring Harbor, NY, Cold Spring Harbor Laboratory Press. 1989: 9.31-9.62.

18. Hunter PR, Gaston MA. Numerical index of the discriminatory ability of typing systems: an application of Simpson's index of diversity. J Clin Microbiol 1988; 26: 2465-2466.

19. Hillis DM, Dixon MT. Ribosomal DNA: molecular evolution and phylogenetic inference. $Q$ Rev Biol 1991; 66: 411-453.

20. Eisenstein BI. The polymerase chain reaction. A new method of using molecular genetics for medical diagnosis. $N$ Engl $J$ Med 1990; 322: 178-183.

21. van Belkum A. DNA fingerprinting of medically important microorganisms by use of PCR. Clin Microbiol Rev 1994; 7: 174-184.

22. Pennington TH, Freebairn EM. Subtyping of Haemophilus influenzae type $\mathrm{b}$ strains from Europe and North America by SDS-PAGE of whole-cell polypeptides: the geographical distribution of subtypes. Epidemiol Infect 1989; 102: 11-19.
23. Jordens JZ, Leaves NI, Anderson EC, Slack MPE. Polymerase chain reaction-based characterization of noncapsulate Haemophilus influenzae. J Clin Microbiol 1993; 31: 2981-2987.

24. Irino K, Grimont F, Casin I, Grimont PAD and the Brazilian Purpuric Fever Study Group. rRNA gene restriction patterns of Haemophilus influenzae biogroup aegyptius strains associated with Brazilian purpuric fever. J Clin Microbiol 1988; 26 $1535-1538$.

25. Loos BG, Bernstein JM, Dryja DM, Murphy TF, Dickinson DP. Determination of the epidemiology and transmission of nontypeable Haemophilus influenzae in children with otitis media by comparison of total genomic DNA restriction fingerprints. Infect Immun 1989; 57: 2751-2757.

26. Smith-Vaughan HC, Sriprakash KS, Mathews JD, Kemp DJ. Long PCR-ribotyping of nontypeable Haemophilus influenzae. $J$ Clin Microbiol 1995; 33: 1192-1195.

27. Mitsuda T, Kuroki H, Ishikawa N et al. Molecular epidemiological study of Haemophilus influenzae serotype b strains obtained from children with meningitis in Japan. $J$ Clin Microbiol 1999; 37: 2548-2552.

28. Murphy TF, Apicella MA. Nontypeable Haemophilus influenzae: a review of clinical aspects, surface antigens, and the human immune response to infection. Rev Infect Dis 1987; 9 $1-15$.

29. Barenkamp SJ, Munson RS, Granoff DM. Comparison of outer-membrane protein subtypes and biotypes of isolates of Haemophilus influenzae type b. J Infect Dis 1981; 144: 480.

30. van Alphen L, Geelen L, Jónsdóttir K, Takala AK, Kãyhty H, Zanen HC. Distinct geographic distribution of subtypes of Haemophilus influenzae type $\mathrm{b}$ in Western Europe. J Infect Dis 1987; 156: 216-218.

31. Saito M, Umeda A, Yoshida S-I. Subtyping of Haemophilus influenzae strains by pulsed field gel electrophoresis. J Clin Microbiol 1999; 37: 2142-2147.

32. Weinberg GA, Ghafoor A, Ishaq Z et al. Clonal analysis of Haemophilus influenzae isolated from children from Pakistan with lower respiratory tract infections. J Infect Dis 1989; 160: 634-643.

33. Giesendorf BALJ, Goossens H, Niesters HGM et al. Polymerase chain reaction-mediated DNA fingerprinting for epidemiologic studies on Campylobacter spp. J Med Microbiol 1994; 40: 141-147.

34. Dalla-Costa LM, Irino K, Rodrigues J, Rivera ING, Trabulsi LR. Characterisation of diarrhoeagenic Escherichia coli clones by ribotyping and ERIC-PCR. J Med Microbiol 1998; 47: $227-234$. 